\title{
The Problem of Climate Change: The Field of Convergence and Interaction between Natural Sciences and the Sociohumanities
}

\author{
V. I. Danilov-Danil'yan ${ }^{a, *}$, V. M. Kattsov ${ }^{b, * *}$, and B. N. Porfiriev ${ }^{c, * * *, \#}$ \\ ${ }^{a}$ Institute of Water Problems, Russian Academy of Sciences, Moscow, Russia \\ ${ }^{b}$ Voeikov Main Geophysical Observatory, Federal Service for Hydrometeorology and Environmental Monitoring, \\ St. Petersburg, Russia \\ ${ }^{c}$ Institute of Economic Forecasting, Russian Academy of Sciences, Moscow, Russia \\ *e-mail:vidd38@yandex.ru \\ **e-mail: director@main.mgo.rssi.ru \\ ***e-mail: b_porfiriev@mail.ru
}

Received June 30, 2020; revised July 7, 2020; accepted July 14, 2020

\begin{abstract}
The relationship and interaction between natural science and sociohumanities knowledge and methods of studying global and regional climate changes and their socioeconomic consequences are analyzed. It is argued that the methodological and instrumental basis of the interaction above involve risk theory and modeling. The key results include a comprehensive assessment and forecast of climatic risks of socioeconomic development, which make up the basis of the development of effective strategies for sustainable longterm development. Ephasized is the counterproductiveness of a straightforward approach to the climate change problem which implies as the main goal of sustainable development the radical reduction of greenhouse gas emissions. The necessity and effectiveness of a systematic approach that provides for the priority of institutional, structural, and technological transformations in society and the economy are emphasized. An important result of these transformations should involve the reduction of anthropogenic impact on the environment, including its climate formation factors, and adaptation to its climate change.
\end{abstract}

Keywords: climate change, risks, socioeconomic development, natural sciences, sociohumanities, convergence, methodology.

DOI: $10.1134 / \mathrm{S} 1019331620050123$

Global climate change, like any grandiose phenomenon that affects the interests of a huge number of people, poses new problems for researchers and forces them to change their approach to many previous tasks and revise traditional ideas and assessments. This applies to almost all areas of human activity, but especially to politics, economic management, and science.

The methodological problems of the latter, identified in connection with the global climate change, are the subject of this article. Attention will be focused on two aspects that most clearly reveal the interconnections and contradictions in the area under consideration: first, within science itself, meaning the similarities and differences between the approaches of natural and sociohumanities disciplines, and second, between

\footnotetext{
\# RAS Corresponding Member Viktor Ivanovich DanilovDanil'yan is Research Supervisor of the RAS Institute of Water Problems (RAS IWP). Vladimir Mikhailovich Kattsov, Dr. Sci. (Phys.-Math.), is Director of the Voeikov Main Geophysical Observatory. RAS Academician Boris Nikolaevich Porfiriev is Scientific Supervisor of the RAS Institute of Economic Forecasting (RAS IEF).
}

the functions of science as a generator of initiative ideas that feed politics, administration, and business, and (by their order) as a developer of methods and means for solving the tasks put forward by them.

It seems that the main questions that are of interest to society, politicians, officials, and entrepreneurs in connection with changes in the global climate boil down to the following: what climate changes can be expected in the foreseeable and distant (until the end of the century and beyond) future and how dangerous are the consequences (economic, social, and environmental) of these changes? How significant is the contribution of the anthropogenic factor to global climate change? In this regard, is it possible to influence, reduce, or slow down climate change, and also estimate the costs required for this? What steps need to be taken to adapt to climate change and how much will these actions cost society?

Today climatology only answers with certainty the question of the contribution of the anthropogenic factor, emphasizing its importance. However, many politicians, entrepreneurs, and even scientists (almost 
always not professional climatologists), and after them journalists often insist on the lack of certainty on this issue. In the spirit of "finding a compromise," they propose not to understand why the climate is changing but simply to adapt, and along the way the reasons for this process will become clear. This strategy does not take into account the specific context in which it is proposed to "engage in adaptation." Meanwhile, adaptation planning requires a clear understanding of the prospects for climate change and, therefore, of its causes. Without knowledge and understanding of these causes, forecasting climate change is impossible, and early adaptation measures are unlikely to be effective [1-3].

Thus, the effectiveness of adaptation is determined by the answers to the remaining questions, which (answers) can only be variant. It makes no sense to try to answer each of them with mathematical precision (using deterministic numbers): we can only talk about the intervals and the probability of falling into these intervals. It remains unclear how wide the range of options is. If it is acceptable, politicians, officials, and entrepreneurs will find a rational strategy. But today, from the standpoint of conventional decision-making theory, the intervals are too wide and the range of options is extremely large.

Prominent Russian climatologist M.I. Budyko wrote in an article on global warming in the late 1990s and early 2000s [4],

One solution or another to the question of the optimal strategy of economic activity in the context of global warming can have very large economic, social, and political consequences. It is easy to understand that it is practically impossible to give a reasonable answer to this question without reliable data on the climatic conditions of the future. Nevertheless, attempts to find an optimal strategy in the absence of reliable materials about the climate of the future are now made quite often.

These words are fully valid even today (with the proviso that the phrase "optimal strategy" in both cases should be put in quotation marks-both in relation to the end of the 1990s and to the present day). But if modern science cannot give answers to the above questions about climate changes in the foreseeable and distant (until the end of the century) future and the danger of their consequences, about the impact on these changes and the cost of this influence that would completely satisfy practitioners, then it is natural to expect from it at least well-grounded recommendations: what to do?

Climatology, like other natural sciences, relying on the laws discovered in physics and other disciplines, builds models that are designed not only to assess and understand the causes of what is happening but also, by accumulating our ideas about the object (climate system), to predict the development of those processes that interest us. Over the past four decades, these models, or rather systems of models, have become extremely complex, especially from the point of view of their interpretation, which has increased the need for close interaction of natural-science and sociohumanities knowledge. To better understand the features of this interaction, a short philosophical and historical excursion is useful.

\section{SCIENCE \\ IN THE POSTNONCLASSICAL ERA}

Academician V.S. Stepin proposed to distinguish three stages in the development of science [5]. The first stage is classical science, when there were simple subject-object relations between the researcher and the object. The object of research was, as it were, the same for all researchers who studied it, be it the movement of planets, gravity, sound propagation, etc. Determinism, the axiomatic method, and, characteristic of the scientific approach, the desire to build everything very strictly and logically, excluding any subjective moments, which was quite feasible in relation to the relatively narrow circle of objects studied at that time, prevailed. It was assumed that the object does not depend on the subject in any way.

The second stage is nonclassical, when, first, recognition of the possibility of different subject-object relations occurred: the researcher, for a variety of reasons, takes his own position in relation to the object (seemingly the same), which is different from his colleagues. Objective criteria for choosing one point of view and rejecting the rest cannot be found, the coexistence of dissimilar, sometimes incompatible (at least for some time) approaches remains, and due to this, a kind of multidimensionality of object perception arises. Second, the subject may be dependent on the researcher. This was most clearly manifested in Bohr's principle of complementarity, according to which the instrumental means used by the physicist have such a strong effect on the objects of the microworld that one cannot be distracted from this influence; it cannot be neglected.

The third stage in the development of science, which Stepin called postnonclassical, came in the 1970 s. It is characterized by both features of the nonclassical stage, but much more was added. The power and availability of computers increased dramatically, and their massive use in scientific research began. Both natural sciences and sociohumanities have moved on to the analysis of systems so complex that two decades before their detailed study seemed impossible. The canons of scientific research in postnonclassical science, unshakable for the previous stages, turned out to be unnecessary constraints that hinder work. It makes no sense to talk about complete systems of axioms when studying the climate or any large economic system. To work with each large system, it turned out to be necessary to involve experts of different, often very far removed from one another, special- 
ties. Interdisciplinarity has become the password for entry into postnonclassical science.

The last $50-60$ years have been characterized by convergence of the methods used by the sociohumanities and natural sciences. This is due to different reasons and manifests itself in different ways. First of all, attention is drawn to the widespread application of the modeling method, which occupies a dominant position in the natural sciences (this is also clearly manifested in climatology). However, social sciences no longer deal without models either. The systems that both sciences are trying to study with the help of computer-aided modeling are very complex systems operating under conditions of uncertainty, evolving, selforganizing, experiencing crises and catastrophes, exhibiting synergy, and undergoing bifurcations (all these words are favorites in the postnonclassical lexicon).

It is important to emphasize that the transition to the third phase of the development of science occurs synchronously in the sociohumanities and natural disciplines. Therefore, the questions about the essence of the natural-scientific approach and research methods, as well as their difference from those used in the sociohumanities, seem to sound quite different today than half a century ago. Now the chasm between them is filled with models: this is not a bridge from which one can fall but the elimination of the very chasm, which no longer exists. Of course, both natural sciences and the sociohumanities have always worked according to a scheme that involved observation, accumulation and systematization of data, hypothesis, collection of additional data for its verification, etc. Common to all sciences was the desire for accuracy and rigor of both methods and results. But ideas about rigor and accuracy, their attainability, and, of course, the methods used remained different. Now, social sciences can no longer do without computer databases, modeling, etc. The face of natural sciences also radically changed with the transition to the study of supercomplex systems: the striving for absolute knowledge became inseparable from the understanding of its unattainability, epistemological relativism influenced the perception of rigor and accuracy and changed their criteria towards convergence with sociohumanities. This rapprochement, perhaps, is the most characteristic feature of the modern stage in the development of science as a whole.

If 60 years ago it had been announced that significantly different models of the climate system would be developed and the professional scientific community would form ensembles of models from them and calculate the resulting characteristics averaged over this ensemble, and then present them to the public as a forecast on behalf of the science of climatology, this, most likely would have caused outrage among scientists. Now almost all professional climatologists understand that it is impossible otherwise.

\section{CLIMATOLOGY \\ IN THE POSTNONCLASSICAL ERA}

A fundamental feature of natural-scientific approaches is their reliance on the laws of physics, which helps, by introducing existing ideas about the climate system into physical and mathematical models, to make forecasts with their help. This approach is fundamentally different, for example, from the extrapolation of observational data into the future, which can only play an extremely limited role in modern climatology. Models based on the understanding of physical and other processes are tested in various ways, including very complex ones [6], improved, and tested again. When, after numerous model experiments, we are convinced that reliable results have been obtained with the help of the models, they are applied in a forecast that can be used not only in climatology itself but also in other sciences, economic, political, etc.

In turn, social or economic problems or challenges can become a prerequisite for natural-science research. Thus, in 1979, the US administration turned to the National Academy of Sciences with a request to assess the sensitivity of the climate to the concentration of $\mathrm{CO}_{2}$ in the atmosphere. The Academy organized a panel chaired by the renowned scientist J. Charney [7], which included the most respected experts who did not participate in the debate around this problem. Charney's group compared the results of the calculations with two independent (both in terms of physical content and mathematical implementation) 3-D complex global climate models, developed by S. Manabe et al. of the Princeton Geophysical Fluid Dynamics Laboratory and J. Hansen of NASA. The group found differences in the details of the results obtained but stated their fundamental agreement on the main point: the climate becomes warmer with an increase in the $\mathrm{CO}_{2}$ concentration in the atmosphere.

The Manabe model showed that, with a doubling of the concentration of carbon dioxide in the atmosphere, there would be a warming of about $2^{\circ} \mathrm{C}$, and the Hansen model, by $4^{\circ} \mathrm{C}$. Based on these estimates, the sensitivity of the global climate to $\mathrm{CO}_{2}$ doubling (idealized, so-called equilibrium sensitivity) was assessed by Charney's group as $1.5-4.5^{\circ} \mathrm{C}$, the most likely value being $3^{\circ} \mathrm{C}$. Charney admitted then that the group "have tried but have been unable to find any overlooked or underestimated physical effects" [8]. Over the decades that followed, when new complex models appeared with improved spatial resolution and increased realism, this estimate, if it was corrected, was not corrected radically. To date, the range of uncertainty remains very significant and has even increased [9]. However, there is still not a single known model-and there are already dozens of them in the world-that demonstrates something other than global warming in response to an increase in the $\mathrm{CO}_{2}$ content in the atmosphere. This can be clearly seen in 
the evolution of the conclusions formulated that the Intergovernmental Panel on Climate Change (IPCC) has regularly been making on global warming for almost three decades of its existence: each subsequent assessment of what is happening with the climate is more categorical than the previous one [10].

Thus, the answer to the question posed by society (or on behalf of society) was given by representatives of natural science and was corrected at every stage of research-with the highest certainty available at that time to climate science. This answer gave rise to many other questions to natural sciences, including those related to the quantitative description of the spacetime aspects of global climate change in the future. Their knowledge would make it possible to move on to effective practical actions-already involving the arsenal of sociohumanities.

\section{ISSUES OF ECONOMIC AND CLIMATOLOGICAL FORECASTING}

The problem of ultra-long-term forecasting in the economy was first posed in a report to the Club of Rome The Limits to Growth, carried out under the leadership of Dennis and Donella Meadows [11]. To answer the question of whether the biosphere will withstand continued economic growth, a simple mathematical model (system dynamics according to J. Forrester [12]) with a small number of variables was used, formally similar to classical physical and mechanical models. However, in contrast to physics and mechanics, the models of which were based on theoretically and/or experimentally substantiated positions, in The Limits to Growth the initial premises appeared rather arbitrary. In particular, scientific and technological progress was not taken into account, and attempts to integrate the corresponding indicators into the model immediately revealed uncertainty of the results that was too high. Nevertheless, the report was an unprecedented success and had a great influence on further work on ultra-long-term forecasting.

Limits to Growth saw the world economy as a kind of syncretic entity. This made it difficult to analyze its development as a system, parts of which interact and develop in different ways, with, accordingly, disaggregation of forecast indicators. An attempt to represent the world divided into groups of countries in the model became the task of the next report to the Club of Rome, Mankind at the Turning Point [13], the authors of which were M. Mesarovic and E. Pestel. Despite the serious scientific shortcomings of this work [14], the very desire to move from primitive micromodels to systemically organized models, consisting of a significant number of relatively independent but interacting blocks, was supported not only by those who were involved in global ecology, the mutual influence of the biosphere and civilization, and superlong-term forecasts of economic dynamics, but also by many researchers who have applied models to solve problems in other subject areas. It was the report Mankind at the Turning Point that laid the foundation for a long series of complex systems of models, composed of different blocks. There are direct and feedback links between them, and the modeling techniques in different blocks are not the same, although there are groups of similar blocks that differ only in parameters and other relatively technical details. This series also includes many other model constructions in natural sciences.

Such systems of models are extremely complex and do not lend themselves to rigorous analytical research; it is rarely possible to assess fairly reliably their sensitivity, stability, etc. In this regard, they are used, rather, as a kind of interlocutor who prompts something, shows something, illustrates something, rejects something, but ultimately does not know the answer to the question he is asked. The demanded, "practical" model should simplify reality, keeping in its description only what is necessary for the purpose of the study; otherwise, using the model, it will not be possible to learn anything new, not to mention the possibility of its application to the economic sphere of life or another.

To predict the economic and social consequences of global climate change and assess measures to slow down and mitigate these changes, it is necessary to translate the results of climatological studies into the sociohumanities field of knowledge for social scientists to use them. Such a translation faces a fundamental difficulty: the difference in time scales. If the time horizon of climatological models is estimated at several tens and often hundreds of years, then economic models beyond the 20- to 25 -year horizon cease to be economic, because the entire toolkit, primarily financial, for various reasons loses its meaning. The main reason is the radical restructuring of the price structure, which occurs in the modern world at least once every 25 years.

Of course, one can try to replace cost categories and indicators with natural ones, for example, with energy indicators (which is sometimes done), distracting from the cost of energy, focusing only on the possibilities of obtaining it in the future with the help of both old and new sources, trying to guess their possible capacity, limitations on their use, etc. However, all this will be far from economic science proper (in both its modern guises-Economics and Political Economy) as a component of sociohumanities knowledge. Therefore, the effectiveness of translating the results of climatological research into the sociohumanities field largely depends on the solution of the above problem of the difference in the time scales of forecasting. One of the main tools for such a solution and, at the same time, the interface between the natural-science and sociohumanities spheres of knowledge, ensuring their convergence for a comprehensive assessment of climate risks, is system modeling (with all its shortcomings).

In addition to the difference in time scales, another fundamental difficulty in translating the results of cli- 
matological studies into sociohumanities knowledge and their use by social scientists is associated with a territorial, or spatial, problem. If we are interested, for example, in the development of the economy in the European part of Russia, then it is no less important than future temperature changes to know about the mode and forecast of precipitation and the state of the hydrosphere in this territory. Will there be more or less water in the Volga, will the water content in the Don remain at the current level or continue to decrease (over the past 25 years, it has decreased by a third)? The attempt to find answers to these questions inevitably leads to analysis and assessment of spatial (regional and even local) features that must be taken into account and reflected in the systems of climate models [15], up to global ones. Hence, the almost avalanche-like growth of the initial information, problems with the stability and sensitivity of model systems, and difficulties in interpreting the simulation results. This applies equally to natural-scientific models, primarily climatological ones, and, of course, to economic models, which leads to the idea that postnonclassical science has more similarities with art than nonclassical and even classical science.

Forecasting climate change and its economic and social consequences and analyzing the possible results of the measures considered in this regard set a completely different (from all previously performed forecast studies), not only quantitative, but primarily qualitative, horizon of vision.

Climate forecasts, identifying and assessing risks and fluctuations in the system, show, in fact, a certain corridor of opportunities along which one can move further and which must be borne in mind when determining the goals and main directions of the country's socioeconomic development, the strategic planning horizon of which is 2-3 times less than the horizon of the climate forecast. The latter, thus, performs the function of a strategic forecast (in terms of the Federal Law On Strategic Planning) [16], setting the space for the goal-setting of a socioeconomic forecast. The principle of rolling planning was consistent with this logic in the Soviet Union at one time.

In turn, the sociohumanities can make a request for climatological research, because ultimately climate change is perceived and evaluated by society not so much as a natural phenomenon but as a source of dangers and opportunities for the development of the society itself. Society must find ways, strategies, and mechanisms to reduce the man-made risks of climatic transformations, including reducing greenhouse gas emissions and the impact on biota, as well as mitigating the effects of natural processes on human health, economic activity, and, in general, on the quality of life and sustainable development. That is, we are speaking about measures of adaptation to changes in the environment.

\section{PUBLIC PERCEPTION OF GLOBAL CLIMATE CHANGE AND ITS CONSEQUENCES}

The adoption of decisions arising from the economic and climatological analysis of the problem of global climate change (to a certain extent they are already noted in the UN Framework Convention on Climate Change (UNFCCC)) [17] at all levelsglobal, national, and municipal, as well as by the business community-is hampered by primarily diverse economic interests. This situation arises whenever it comes to long-term decisions: they are made, then, as a rule, in conflict with the current, short-term economic interests of various social groups and sometimes in conflict with almost the entire population.

Climate change is no exception in another respect either. In the modern "society of the spectacle" (according to G. Debord [18]), any serious, largescale, and especially global idea is inevitably politicized, mythologized, and vulgarized, and becomes a source of unjust income for those who know how to profit from absolutely everything. The performances in this society of the spectacle are naturally directed by producers with great financial resources. It is they who, if the conclusions arising from climatological studies contradict their interests, try to turn the climate problem upside down in the public consciousness, qualifying all climate protection activities as religious with attributes of missionary behavior. Of course, in no way can this be attributed to the work of scientists and the activities of the IPCC, although in fairness we note that the "performances" organized by other producers give a real reason for such interpretations.

From the representatives of the corporate sector, including the largest companies, at Russian and international forums, one can hear that in long-term planning all possible scenarios of expected future climate changes are used; therefore, they are ready for both a cold snap and a warming. Such an attitude may be the result of ignoring the problem in the spirit of the Marquise de Pompadour's mental set "after us the deluge" (the problem is, after all, super-long-term), or a lack of understanding of the true scale and complexity of the problem, or recognition of powerlessness. Be that as it may, from an economic point of view, this is an irrational approach: only those with unlimited possibilities can be ready for any outcome. It is unrealistic and it is not necessary to prepare for all conceivable scenarios of climate change; it is quite acceptable to restrict ourselves to the assumption of an increase in the average global surface temperature over a century and, on this basis, strive for the increase to be closer to the lower, not the upper, limit of the specified interval, and to prepare strategies for adaptation measures for various variants of regional manifestations (primarily in the form of expected changes in the range of climate variability for a given territory) and for the consequences of climate change. 
Of course, in all this, there is a lack of confidence in climatology, because it (all the more, coupled with economic science) gives less than we would like to get from it. The situation is aggravated by the aforementioned "performances" arranged around it by opponents, or "well-wishers," ignorant or devoid of an elementary sense of proportion and ethics of behavior. The answer to the most important question, how the results of climatological studies are perceived, and how correctly they are interpreted, reveals numerous examples of complete illiteracy, primarily in the media, the circulation of which is several orders of magnitude higher than that of even popular-science (not to mention scientific) literature. As soon as the temperature at any place on the earth's surface drops by $20^{\circ} \mathrm{C}$ per day (quite an ordinary phenomenon), there will certainly be a TV or radio commentator who will say, "What kind of warming are we talking about!? It is clear that an ice age is coming!" One could not help to recall the words of A.I. Voeikov [19],

\begin{abstract}
Almost every year it happens that an unusually high or low temperature attracts everyone's attention and leads to lengthy arguments that the oldest people do not remember such weather. To explain these anomalies, they resort to very different reasons .... Usually they do not take the trouble to find out whether the same weather is everywhere on the globe at this time.
\end{abstract}

In this regard, numerous publications in the media and even in reputable scientific journals in connection with the coronavirus pandemic note a tangible positive effect of the restriction regime on the volume and dynamics of emissions, including greenhouse gases. Particular attention is focused on the date April 7, 2020: it was on this day that the largest number of people in the world were quarantined and the most significant reduction in greenhouse gas emissions was observed, which on that day fell by $17 \%$ compared to the same date of the previous year (in some countries the level of decline reached 26\%) [20]. The authors of such publications emphasize the need to use this "window of opportunity" to further reduce emissions in order to stabilize the climate. At the same time, the natural-scientific understanding of the climate change phenomenon, which is associated primarily with the accumulated volume of greenhouse gases in the atmosphere, as well as the inevitability of getting back on track after the end of quarantine, is ignored or absent. Indeed, less than two months later, there was a rebound from the aforementioned $17 \%$ decrease in global daily $\mathrm{CO}_{2}$ emissions, and by June 11, 2020, the gap from 2019 had narrowed to $4.7 \% .^{1}$ A similar phe-

\footnotetext{
${ }^{1}$ For comparison, in Russia, in April 2020, the volume of daily emissions compared to April 2019 was 1.12 million tons of $\mathrm{CO}_{2}$ lower; by June 11, 2020, it decreased to 200000 tons; in the United States, these figures were, respectively, 4.5 million and 1.1 million tons. In Europe (EU + Great Britain), it was 2.5 million and 758000 tons [21]. This means a reduction in the gaps by $5.6,4.1$, and 3.3 times, respectively.
}

nomenon, albeit on a smaller scale, took place during the global financial crisis 12 years ago, when in 2009 , following a $2 \%$ drop in global GDP, the volume of greenhouse gas emissions decreased by $1 \%$, but already by 2010 it had increased by $6 \%$, and in the period 2010-2016, in the course of a vigorous economic recovery, by $12 \%$. Moreover, according to the Mauna Loa Observatory in Hawaii, in the last days of May 2020, a $\mathrm{CO}_{2}$ concentration of $417 \mathrm{ppm}$ was recorded, a record for millions of years and significantly higher than the level of $415 \mathrm{ppm}$ a year earlier [22].

In this regard, it seems that optimism about a significant reduction in greenhouse gas emissions due to the pandemic quarantine, on the one hand, is a consequence of the misunderstanding that the pandemic did not affect the situation with global climate change radically but not even at all; in other words, the point is ignorance of the basics of climatology. On the other hand, calls to start immediately (within six months at the most) a radical restructuring of Russia's energy sector and in the next decade to reduce many times the share of hydrocarbons (including gas) in it, hold back the growth of the share of nuclear power plants, and increase by an order of magnitude the contribution of renewable energy sources are ignorant or a failure to grasp the real economic situation in the country and the laws of the economy.

Thus, the process of convergence of natural-scientific and sociohumanities approaches to the study of and search for solutions to the problem of global climate change and their socioeconomic consequences, which is actually happening, and at a rather fast pace, but very unevenly, with noticeable difficulties and contradictions, is even more relevant. Even representatives of other natural-science disciplines do not always agree with the assessments and conclusions of climatologists. Mutual understanding and trust take place among those who are engaged in postnonclassical constructions, work in interdisciplinary projects, etc. However, between those who in their fields, following the best traditions, study classical problems, and "postnonclassics," there is often both mutual misunderstanding and mistrust. More than once I have heard, for example, from geologists that the anthropogenic impact on the climate cannot be significant, since natural forces (volcanism, earthquakes, etc.) are many times greater than the capabilities of modern man. In the offices of these scientists, often outstanding specialists, there is a portrait of V.I. Vernadsky, who wrote almost a century ago, "Mankind, taken as a whole, is becoming a powerful geological force" [23, p. 241]. Since then, this power has grown exponentially. However, the contradiction is not embarrassing, not explicated, and perhaps not even noticed.

At the same time, a significant part of social scientists and humanities scholars is not yet ready for a competent interpretation of the data of climatologists, 
ecologists, and geographers. Even in reputable scientific journals of the sociohumanities profile, there is often a misunderstanding of the significance of what is being done today in natural sciences, particularly in the field of climatology. Psychological barriers remain between representatives of different scientific communities, which can be eliminated through dialogue, but here mutual trust is necessary, which, as you know, is easy to lose, but difficult to win, and even more so to restore. Equally important is the level of trust of the authorities and business in the scientific community, as well as in society as a whole in business and government, and vice versa. This issue is complex and acute on the agenda not only in our country but practically in any country in the world.

With regard to the problem of climate change and its consequences, to the climate topic in general, the interpretation of scientific information becomes especially difficult. Practically all people use weather reports published by numerous media outlets. The attitude to the quality of these forecasts is different, but the perception by ordinary consumers of the data contained in them as information not just about the weather but also about the climate is practically unanimous. Very few people know, or even understand, that weather forecast data are not identical to climatic characteristics, that the latter are observational data averaged over a sufficiently long period, usually at least 30 years, including those contained in weather reports. Note that we are speaking about relatively simple things: the perception and understanding of the primary information of observations. What can we say about the interpretation of the simulation results, the understanding of which at the level necessary for the user (economist, sociologist, psychologist, etc.) requires a lot of effort on his part and immersion in the topic. Goodwill is needed on both sides: on the part of those who build models and from those who must use their results in their subject and/or practical field.

\section{TACKLING THE CLIMATE CHANGE PROBLEM}

Any negative external impact on the system, which is barely kept within the boundaries of stability, puts it in an even more difficult position, worsens the current situation, and exacerbates destructive processes. Threats caused by changes in the global climate reveal more sharply the shortcomings of the existing civilization and emphasize and intensify the negative that takes place in a stationary climate. This is also demonstrated by the COVID-19 pandemic, the impact of which on the world community and the economy has aggravated and at the same time clearly demonstrated the shortcomings of different social systems. No matter how you build a hierarchy of global threats, you have to admit that what is bad only gets worse with climate change.

The World Economic Forum's 2020 report on global development risks for the coming decade [24] highlights failures in climate policy, as well as extreme weather (!) events and natural disasters, above the consequences of conflicts and wars with the use of weapons of mass destruction, and not only in terms of probability (which is understandable) but also in terms of the scale and degree of danger of its impact on society and the economy, and this is difficult to understand.

A kind of shading and dissolution of the problem of global climate change in the series of threats to sustainable development, as well as to international and national security, is due to the remoteness of many of its consequences in time and the distance of the time horizon of climate forecasts. The illusion of the possibility of postponing decisions on measures to reduce future damage is created-in our opinion, a characteristic feature of climate risk compared to the same pandemic, which required an immediate response, the delay of which has led to large social losses and significant economic damage in a number of countries.

Another feature of climate risk is its perception as real, significant, and global, not in its pure form but through the implementation of other dangerous phenomena and processes, primarily extreme weather situations, as well as epidemics and pandemics. When there is a wave of heat or cold, a snowless or, on the contrary, snowy winter, severe drought or, conversely, continuous showers, etc., they often speak about the climate, although, in fact, it is not really about it. Climate change, in fact, is made up, among other things, of such weather phenomena, but even their sum (not to mention other important climate formation factors) is not identical to it.

The specific features of climate change, the perception and assessment of them, including their role simultaneously as an amplifier and indicator of the vulnerability of socioeconomic systems, the combination of an indirect and delayed cumulative effect on society with a sudden destructive effect of emergencies of a hydrometeorological (climatic) nature allow us to formulate an approach to substantiating an effective strategy for sustainable development, taking into account the climate change factor. Until recently, the desire to find and justify a simple universal solution to the climate problem has completely dominated and still retains a strong position at the international and national levels. However, both the UNFCCC and the Paris Agreement on climate explicitly provide for the principle of differentiation of both responsibility for the negative, human-induced climate change and policies aimed at mitigating these changes and their consequences. 
As Academician Budyko noted in the late 1990s, such a desire is based on the following assumption [4]:

With unknown features of climate change in the era of global warming, these changes can lead to catastrophic consequences, which it is desirable to avoid. The only effective method to achieve this goal is allegedly to reduce greenhouse gas emissions, especially carbon dioxide, which has the greatest impact on global warming.

Almost 30 years of experience in implementing the UNFCCC has proven that such an approach, which underestimates the socioeconomic specifics of the countries of the world, including Russia, as well as the importance of adaptation as an effective mechanism for reducing climate risks, is not a panacea and often leads to a dead end.

The foregoing in no way means underestimating the problem of climate change and its consequences, which is fully included in the UN Sustainable Development Goals. It is about something else, namely, about choosing an effective strategy of action to solve this problem. For us, the counterproductiveness of the approach that assumes that the global temperature does not exceed any a priori given value as a strategic goal, for the implementation of which alternative scenarios of socioeconomic development are being developed using methods of retropolation [25] or reverse induction, is obvious [26]. This approach is appropriate and productive for socioeconomic planning with a horizon from three (short-term planning) to 1520 years (long-term planning). As applied to the problem of climate change and its consequences, it is ineffective at best, but many politicians and experts abroad and in Russia, in particular, zealous supporters of the low-carbon development strategy in its aggressive version, have continued to insist on it for many years [27, 28]. To reduce climatic development risks, strategic decision makers should do the following: in the field of goal-setting, proceed from the priority of socioeconomic goals of sustainable development in relation to climatic ones (see below); in the field of action planning to achieve goals, to provide for a consistent (albeit dynamic!) modernization of the structure, production and technological base of the economy, as well as to change (ecologize) the existing model of social behavior, relying on the methods of direct induction in this planning [26, 29].

An effective solution to the problem of climate change and its consequences can only be mediated, implemented within a more general paradigm of sustainable socioeconomic development. This approach is by no means new: it is the core of the well-known concept of mainstreaming-embedding solutions to climate problems in the policy of socioeconomic development, which has been declared for a number of years in official documents on climate at the international and national levels (see, for example [30]). However, in practice, with rare exceptions, this decla- ration is replaced by the opposite action-regular and not unsuccessful attempts to embed socioeconomic policy in solving climate problems. At the same time, a fundamental circumstance is overlooked: an unstable system that does not ensure the reproduction of the natural environment, health of the human population, and mechanisms of social stabilization, even in the absence of man-made greenhouse gas emissions, is unable to restrain the forces of self-destruction inherent in it and degrades.

Climate is, first of all, a necessary condition and factor of human life, its development, and the quality of life; this is how it is perceived by society. Like it or not, this approach is not free from anthropocentrism, but the anthropocentrism of a healthy person, which does not presuppose human well-being at the expense of the rest of the biosphere, but only within it and together with it. Based on this, an effective sustainable development strategy should include the following:

First, improving the quality of management of socioeconomic development, in a broader sense, the quality of civilization as a whole; this will ensure a reasonable balance between the dynamics of economic growththe main source of income-and the stability of the socioeconomic system-the imperative of its longterm existence.

Second, bearing directly in mind the factors of climate formation, the implementation of an effective environmental policy, aimed at mitigating the severity and reducing the scale of environmental problems, primarily air pollution (toxicants hazardous to human health), as well as maintaining the quality of natural ecosystems, forests and wetlands, which (together with oceanic systems) make a decisive contribution to reducing the load on the atmosphere absorbing some of the carbon from the atmosphere and retaining it.

Third, ensuring the priority of the socioeconomic goals of sustainable development (overcoming poverty and reducing poverty, eliminating hunger and strengthening food security, improving human health, and ensuring dynamic economic growth that covers the entire working-age population, which are set by the UN in the list of sustainable development goals until 2030 above the climate problem)-in contrast to the latest tendency in the policy of a number of states, primarily the EU member states, to put the problem of climate change at the top of the list of threats and risks to sustainable development. This is fully consistent with the priorities of the medium- and long-term (five- and ten-year period, respectively) development of Russia, defined in the Decree of the President of the Russian Federation of May 7, 2018, No. 204 On National Goals and Strategic Objectives of the Development of the Russian Federation for the Period up to 2024 and developing it by the decree of July 21, 2020, On the National Development Goals of Russia until 2030. 
It is no coincidence that the current rate of reduction in greenhouse gas emissions does not meet the requirements of the Paris Agreement not to exceed the warming threshold of $2^{\circ} \mathrm{C}$ by the end of this century compared to the preindustrial era. This, most likely, will continue if the climate problem, on the one hand, continues to dominate the priorities of global development, and on the other hand, while solving it, the policy of accelerated reduction of greenhouse gas emissions will continue to prevail, including in terms of costs, which are several times (or even an order of magnitude) higher than the cost of proactive adaptation.

Quite numerous and influential supporters of such an approach both in the world and in Russia appeal to the Paris Agreement, which requires all countries that have ratified it, including Russia, to elaborate a longterm development strategy with low greenhouse gas emissions. At the same time, the fundamental position of the same document is ignored, according to which both the parity of measures to reduce emissions (and, what is important, net emissions, taking into account not only the reduction of emissions but also the absorption of greenhouse gases) and adaptation measures, and the need for action on reduction of manmade greenhouse gas emissions in the context of eradication of pauperism and reduction of poverty.

It is significant that in the names of a number of national strategies adopted in pursuance of the above requirement of the Paris Agreement by the states of the world, ${ }^{2}$ including the EU countries, the leaders of global climate policy (specifically Great Britain, Germany, and the Czech Republic), greenhouse gases are not mentioned, and broader formulations are used. For example, take the Climate Action Plan (Germany), the Clean Growth Strategy (UK), and the Long-Term Strategy under the Paris Agreement (Japan). These strategies are positioned as aimed at mitigating climate risks, although, of course, due attention is paid to the task and methods of reducing greenhouse gas emissions in these documents. It is important that all officially adopted strategies include measures for adaptation to climate change; thus, the principle of the Paris Agreement on the equivalence of both groups of climate policy measures is implemented.

Climate change is a global problem, and its solution is possible only in relation to civilization as a whole, which implies solidarity between countries and peoples of the world. However, political and economic interests encourage and will continue to encourage some participants in the global process to take a special position and, to defend it, resort to making claims to other countries about the alleged inconsistency of their actions with high climatic goals. At the same

\footnotetext{
2 As of March 2020, strategies have been adopted by 15 countries, including 10 developed and 5 developing countries.
}

time, the recently popular mechanism of sanctions or other restrictive measures, such as the border carbon tax, is coming to the fore. That is why the foreign policy of Russia should have a set of measures both to counteract such practices and to adapt to the new situation, including efforts to reduce the impact on the climate system effectively. Here one should rely on a combination of the achievements of domestic science in the natural-science and sociohumanities sphere, primarily in modeling and forecasting.

Academician V.V. Ivanter emphasized [31, p. 127],

Forecasting is not an attempt to predict the future but a way to assess possible problems that arise from solving urgent problems. In other words, the solution to today's problem predetermines the emergence of a future problem, and in this sense a forecast is not an assessment of the well-being of the future in the spirit of Jules Verne but an assessment of future problems in the spirit of the mature Strugatskii brothers.

Such analysis and assessment, as an essential part of risk management, should be carried out continuously. This is a process during which certain plans, programs, strategies, international treaties, and other events will surely arise. But the main thing is that this process presupposes constant feedback: the analysis of a possible future must be constantly adjusted depending on scientific results and the emergence of new knowledge. Using the usual template-a long-term program is developed, then implemented, and its results, including the bleak ones (nothing has changed, efforts have not yielded results), are summed up 15-20 years later-will not solve the problem of global climate change. Managing the risks of climate change for society and the economy must be justified, comprehensive, and controllable, which requires reliance on science, its interdisciplinary potential, and the convergence of natural-science and sociohumanities approaches and methods.

\section{CONCLUDING REMARKS}

The problem of global climate change and its consequences for sustainable socioeconomic development poses the most difficult tasks for modern science and practice. Their solution requires close cooperation of all active and potential participants in this process: scientists and specialists in the natural sciences and sociohumanities; producers and industry and regional consumers of climate information; decision makers at all levels of government (from corporate and municipal to federal); nonprofit (public) organizations; and the media.

Such interaction presupposes knowledge and understanding of the existing opportunities, limitations, and difficulties in the practical use of knowledge about the climate, its changes, and the consequences of these changes for the environment and society. Here an important role is played by trust in the scientific 
and expert community and understanding of its desire to obtain objective research results and give them a correct comprehensive assessment. There is a lot of work to be done to use the opportunities that high technologies provide, especially complex physical and mathematical models. Intensive development of methods, models, and technologies is required to ensure adequate application of the results of climate monitoring and modeling.

It is extremely important that the indicated interaction of the participants in the process ensures a clear separation of their functions, because the scientific community is not the subject of political or economic decision making, and the rest of the interested parties cannot be regarded as a source of scientific knowledge. Unfortunately, dilettantism has been triumphant lately-the result of a misunderstood freedom of speech, which opens up boundless space for illiterate and irresponsible judgments in public dialogue around the climate problem. This is a tangible obstacle to building public dialogue and meaningful climate policies.

It is fundamentally important that scientific results-not only of professional climatologists and representatives of other natural sciences but also specialists in social scientists and the humanities-are available for understanding by each other, as well as by the public and decision makers. Scientists and experts are responsible for ensuring that their answers to questions and requests from the authorities and society on the climate problem and its solution correspond to the modern level of scientific knowledge, not simplified even in the name of facilitating their understanding by nonspecialists. This means that the problem of interpreting the results of climate change studies and their socioeconomic consequences becomes an imperative for the scientific community, implying increased integration of natural-science and sociohumanities knowledge through the use of the risk-based approach methodology and modeling methods. We are also speaking about a closer and more effective interaction between the scientific community and scientific media, including in the search for a common language.

\section{FUNDING}

This study was supported by the Russian Foundation for Basic Research, project no. 18-00-00600 (18-00-00596 and 18-00-00599).

\section{REFERENCES}

1. The Adaptation Gap Report 2017 (UNEP, Nairobi, 2017).

2. Adapt Now: A Global Call for Leadership on Climate Resilience. Report of the Global Commission for Adaptation. September 2019. https://cdn.gca.org/assets/201909/GlobalCommission_Report_FINAL.pdf.
3. 25 Years of Adaptation under the UNFCCC. Report by the Adaptation Committee (United Nations Climate Change Secretariat, Bonn, Germany, 2019).

4. M. I. Budyko, "Global Warming," in Climate Change and Its Consequences (Nauka, St. Petersburg, 2002), pp. 7-12 [in Russian].

5. V. S. Stepin, The Philosophy and Methodology of Science (Akad. Proekt, Moscow, 2015) [in Russian].

6. V. V. Kattsov, V. P. Meleshko, V. A. Govorkova, et al., "Models designed for future climate change assessment," in Roshydromet Assessment Report "Climate Change and Its Consequences in the Russian Federation" (Moscow, 2008), Vol. 1, pp. 112-151 [in Russian].

7. S. Weart, The Discovery of Global Warming (Harvard Univ. Press, Cambridge, MA, 2008).

8. Carbon Dioxide and Climate: A Scientific Assessment (National Academy of Sciences, Washington, DC, 1979).

9. G. A. Meehl, C. A. Senior, V. Eyring, et al., "Context for interpreting equilibrium climate sensitivity and transient climate response from the CMIP6 Earth system models," Sci. Adv. 6 (26) (2020).

10. V. M. Kattsov, P. V. Sporyshev, and I. L. Karol', "Evolution of scientific ideas about the causes of climate change," in Second Roshydromet Assessment Report on Climate Change and Its Consequences in the Russian Federation (Rosgidromet, Moscow, 2014), pp. 236-248 [in Russian].

11. D. H. Meadows, D. L. Meadows, J. Randers, and W. W. Behrens, The Limits to Growth, 2nd ed. (Potomac Associates, 1974).

12. J. W. Forrester, World Dynamics (Wright-Allen, 1971).

13. UA Economy in the Future (Problems and Forecasts) (Progress, Moscow, 1982) [in Russian].

14. V. I. Danilov-Danil'yan and A. A. Ryvkin, "Global modeling," in Economic Encyclopedia. Political Econo$m y$, in 4 vols. (Sovetskaya Entsiklopediya, Moscow, 1980), Vol. 4, pp. 613-618 [in Russian].

15. I. Shkolnik, T. Pavlova, S. Efimov, and S. Zhuravlev, "Future changes in peak river flows across northern Eurasia as inferred from an ensemble of regional climate projections under the IPCC RCP8.5 scenario," Climate Dynamics 50, 215-230 (2018). https://doi.org/10.1007/s00382-017-3600-6

16. Federal Law On Strategic Planning in the Russian Federation of June 28, 2014, no. 172 (edition of July 18, 2019). www.consultant.ru/document/cons_doc_LAW200404/a514cfa65b601d1f631aa5b09aeb95465982f024/\#dst100008. Cited June 29, 2020.

17. United Nations Framework Convention on Climate Change. https://www.un.org/ru/documents/decl_conv/conventions/climate_framework_conv.shtml. Cited June 29, 2020.

18. G. Debord, La Société du spectacle (Buchet/Chastel, Paris, 1999).

19. A. I. Voeikov, "Nonperiodic temperature changes and their explanations," in A. I. Voeikov, Selected Works, Ed. by A. A. Grigor'ev (Izd. Akad. Nauk SSSR, Moscow, 1952), Vol. 3, pp. 15-33 [in Russian]. 
20. C. Le Quéré, R. B. Jackson, M. W. Jones, et al., "Temporary reduction in daily global $\mathrm{CO}_{2}$ emissions during the COVID-19 forced confinement," Nature Climate Change 10 (7), 647-653 (2020). https://doi.org/10.1038/s41558-020-0797-x

21. C. Le Quéré, R. Jackson, M. Jones, et al., "Supplementary data to: Le Quéré et al. (2020). Temporary reduction in daily global $\mathrm{CO}_{2}$ emissions during the COVID-19 forced confinement (Version 1.0)" Global Carbon Project (2020). https://doi.org/10.18160/RQDW-BTJU

22. Rise of carbon dioxide unabated. Seasonal peak reaches 417 parts per million at Mauna Loa observatory. https://research.noaa.gov/article/ArtMID/587/ArticleID/2636/Rise-of-carbon-dioxide-unabated. Cited June 21, 2020.

23. V. I. Vernadsky, Scientific Thought As a Planetary Phenomenon (Nauka, Moscow, 1991), Part 1 [in Russian].

24. World Economic Forum: The Global Risks Report 2020 (WEF, Geneva, 2020).

25. J. Robinson, "Unlearning and backcasting: Rethinking some of the questions we ask about the future," Technol. Forecast. Soc. Change 33 (4), 325-338 (1988).
26. J. von Neumann and O. Morgenstern, Theory of Games and Economic Behavior (Princeton Univ. Press, Princeton, 1953).

27. B. N. Porfiriev, "The low-carbon development paradigm and climate risk reduction for the economy," Stud. Russ. Econ. Dev. 30 (2), 111-118 (2019).

28. B. N. Porfiriev, A. A. Shirov, and A. Yu. Kolpakov, "Low-carbon development strategy: Prospects for the economy of Russia," Mir. Ekon. Mezhdunar. Otn. 64 (9), 22-33 (2020).

29. R. Stalnaker, "Belief revision in games: Forward and backward induction," Math. Soc. Sci. 36 (1), 31-56 (1998).

30. Climate Change for Forest Policy-Makers-An Approach for Integrating Climate Change into National Forest Policy in Support of Sustainable Forest Management-Version 2.0. FAO Forestry Paper no. 181 (FAO, Rome, 2018).

31. Economics according to Academician Ivanter, Ed. by B. N. Porfiriev, M. N. Uzyakov, A. A. Shirov, A. E. Ivanter, and I. V. Zubkov (Nauka, Moscow, 2020) [in Russian].

Translated by B. Alekseev 